\title{
Agonística em tempos de empreendedorismo de si: Desassossegos no trabalho com a política pública de assistência social
}

\author{
Bruno Cerqueira Gama \\ Cláudia Abbês Baêta Neves
}

\section{RESUMO}

Este artigo problematiza a política pública de assistência social brasileira através da reflexão conceitual sobre o governo da vida pautado numa lógica neoliberal. Para tanto, utilizando-se de uma breve narrativa confeccionada entre lembranças e esquecimentos que permearam experiências de trabalho e pesquisa nesta política entre 2011 e 2017, questões sobre o empreendedorismo de si mesmo aparecem como um norte cada vez mais presente na execução dessa política. Partindo destas reflexões e dos questionamentos éticos sobre que vida desejamos viver e o que estamos a fazer nós mesmos, indagamos: como e por que continuar a operar políticas públicas na nossa atualidade? As narrativas, utilizadas como recurso metodológico deste ensaio teórico-reflexivo, nos auxiliam a problematizar o entretecer de fazeres nesta encruzilhada ética a partir da qual, por fim, aposta-se na invenção do caráter público como fundamental na atuação profissional no Sistema Único de Assistência Social (SUAS).

Palavras-chave: psicologia; assistência social; biopolítica; caráter público; empreendedorismo de si.

\section{ABSTRACT}

Agonistic in times of entrepreneurship of oneself: Restlessness in the work with the public policy of social assistance

This article discusses the public policies of Brazilian social assistance through the conceptual reflection on the government of life based on a neoliberal logic. For this purpose, using a brief narrative made between memories and forgetfulness that permeated work and research experiences in this policy between 2011 and 2017, questions about entrepreneurship of oneself as a north, often present in the professional exercise in this policy, emerge. Starting from these reflections and the ethical questions about what life we want to live and what we are doing about ourselves, we ask: how and why continue to operate public policies nowadays? The narratives, used as a methodological resource of this theoretical-reflexive research, helped us to problematize the interweaving of actions at this ethical crossroads, from which, finally, bets on the invention of the public character as fundamental in the professional performance in the Sistema Único de Assistência Social (SUAS).

Keywords: psychology; social assistance; biopolitics; public character; entrepreneurship of oneself.

Numa cidade qualquer, um efusivo palestrante esbraveja seguramente acerca da postura do vencedor para aproximadamente cento e cinquenta adolescentes. Conduta esta que, dentre vários tônus, indica que o queixo deve andar paralelo ao chão enquanto o corpo se movimenta com pisadas cuja firmeza se traveste de elegância. Em plena era do "C-H-A" (mantra que, segundo o orador, singulariza o nosso tempo, cuja ênfase está no pacote pré-fabricado de "Conhecimentos, Habilidades e Atitudes") vende-se uma modulação do vencedor cujo destaque se faz por essa tríade que acentua na atualidade a já batida iniciativa do indivíduo isolado e sua criatividade obediente. "Não adianta ser o revolucionário com suas ideias doidas!", profes-

\section{Sobre os Autores}

B. C. G.

orcid.org/0000-0002-8760-0580 Universidade Federal de Sergipe (UFS) - Aracajú - SE

brunocegama@gmail.com

\section{A. B. N.}

orcid.org/0000-0002-4615-4377

Universidade Federal

Fluminense (UFF) - Niterói - RJ

abbes@luma.ind.br

\section{Direitos Autorais}

Este é um artigo de acesso aberto e pode ser reproduzido livremente, distribuído,

transmitido ou modificado, por qualquer pessoa desde que usado sem fins comerciais. 0 trabalho é disponibilizado sob a licença Creative Commons CCBY-NC.

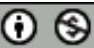




\section{WIIITERACÃO EM ET. PSICOLOGIA}

sava o elegante palestrante.

Garotos em busca de fórmulas para vencer, para dominarem os cacoetes de uma trajetória de sucesso que deveria ser previamente planejada. $\mathrm{Na}$ era do $\mathrm{C}-\mathrm{H}-\mathrm{A}$, alerta o orador, é muito importante saber diferenciar atitude de ousadia para se fazer vencedor. Confecção esta que se inscreve na pisada firme, com o peito estufado e que versa sobre uma fé cega na "hora certa"; num manejo, num preparo da vida atento, alerta e pré-disposto para as oportunidades que possivelmente hão de surgir quando se prepara como convém. Trata-se de um jogo entre o querer do sujeito e o mundo.

Nesse jogo que invoca saberes, produção de corpos e planejamentos de vida, Michel Foucault (1997) e os seus diagramas de saber-poder que incidem na vida, ainda presentes em nossa atualidade, podem ser importantes ferramentas para problematizar tais lógicas. O pensador francês afirmara dois grandes diagramas que nos são contemporâneos, quais sejam: as disciplinas anátomo-políticas, que visam o corpo como uma máquina de adestramento, ampliando suas aptidões, extorquindo suas forças em paralelo ao crescimento de sua utilidade e docilidade, integradas em sistemas de controle eficazes e econômicos; e o biopoder, que, tendo como suporte os processos biológicos, caracteriza toda uma série de intervenções e controles reguladores centrados no corpo, transpassado pela mecânica do ser vivo no que diz respeito à proliferação, aos nascimentos e à mortalidade, ao nível de saúde, à duração da vida, à longevidade, com todas as condições que podem fazê-la variar. Com esses dois polos, há, portanto, uma proliferação de técnicas diversas e numerosas para obterem a sujeição dos corpos e o controle das populações, demarcando o normal e o anormal, tendo como base, primeiramente, a colocação de um modelo considerado ótimo que é construído em função de certo resultado, e, logo após, consiste em procurar tornar as pessoas, os gestos, os atos, conformes a esse modelo, sendo a definição de normal ou anormal pautada precisamente na capacidade ou não de se conformar a essa norma. Trata-se de poder olhar no espeIho e, a despeito dos obstáculos externos, enxergar um vindouro vencedor.

$O$ que podemos perceber, relacionando os diagramas de poder supracitados e o mantra do "C-H-A", é que a gestação do vencedor obedece aqui não somente a uma tecnologia de disciplina-normalização, mas também a de uma ação sobre o ambiente que tende a "modificar a distribuição das cartas do jogo, não a mentalidade dos jogadores" (Foucault, 2008b, p. 356).

Esse aglomerado rasteiro de receitas para o sucesso servia de abertura para um projeto de orientação profissional (POP) para adolescentes que frequentavam os Serviços de Convivência e Fortalecimentos e Vínculos (SCFV) de alguns
Centros de Referência em Assistência Social (CRAS) daquela cidade.

O projeto, confeccionado por psicólogos, assistentes e educadores sociais que atuam em níveis preventivos com populações em situação de vulnerabilidade social, se desenvolveu em várias etapas que abrangiam ações como palestras e visitas a locais de trabalho, tanto governamentais quanto não-governamentais, com o intuito de motivar o público-alvo para a confecção de um projeto de vida no campo profissional. A motivação se atualizava através da oferta de noções sobre o mundo do trabalho, possibilitando, assim, o acesso a ferramentas que auxiliassem na identificação das vocações profissionais.

Direito à saúde, moradia, educação, segurança alimentar, saneamento básico, etc. - é em relação à capacidade de resposta dos indivíduos frente às ameaças de usufruto a esses indicadores, como também em relação à vaga ideia de "privação e fragilidade dos vínculos", que a noção de vulnerabilidade social é formulada. Para Gama (2017), esta pode ser, resumidamente, definida como a incapacidade de enfrentar os riscos ou como a impossibilidade de "manejar ativos" para proteger-se. Neste sentido, o capital social, humano e físico, e a estrutura das famílias no enfrentamento de muitos riscos, são reveladores das relações e "estruturas das oportunidades" que indicam grupos mais ou menos vulneráveis numa avaliação que envolve a compreensão do perigo envolvido (eventos que causam dano) e a capacidade de resposta, absorção e ajustamento que aquele grupamento humano (família e/ou comunidade) ou território possuem para enfrentar o perigo. É como efeito dessa lógica que podemos entender por que a criança em situação de rua é considerada mais vulnerável do que um adulto. Sobre este último, supõe-se toda uma experiência de vida, todo um processo de "desenvolvimento biopsicossocial" que lhe condensa um repertório maior de possíveis respostas às situações de risco do que um criança ainda em fase de desenvolvimento, com pouco repertório para enfrentar as inúmeras vicissitudes da vida.

Ainda segundo Gama (2017), nesse campo - o das vulnerabilidades sociais - , se estabelece uma série de práticas normativas que devem guiar os fazeres de técnicos engajados. Psicólogos, assistentes e educadores sociais que atuam no Sistema Único de Assistência Social (SUAS) devem, em conjunto com os usuários e de forma pró-ativa, inserir-se em situações-problema e intervir com o objetivo de minimizar e/ ou gerir tais índices de vulnerabilidade.

Todavia, o palestrante parecia atingir não só aos jovens, mas também aos profissionais ali presentes. Havia sido indicado por um dos técnicos que já o vira versar sobre o " $\mathrm{C}-\mathrm{H}-\mathrm{A}$ " e se sentira motivado a continuar sua busca por um lugar mais confortável ao sol. A oratória dispunha seus elementos 
com o objetivo da correta participação no jogo concorrencial de busca por emprego. Jogo que perversamente se esquiva do fato de que não há lugar para todos no mercado de trabaIho e se concentra na luta individual sem necessariamente questionar os enquadres normativos em meio à perversa desigualdade social que atravessa os corpos. Jogo que preza pelo aumento da renda monetária para os seus vencedores e minimiza lances afeitos a possíveis (e desejáveis?) impactos redistributivos no campo das políticas públicas.

O mantra do $\mathrm{C}-\mathrm{H}-\mathrm{A}$ visa posicionar melhor os jogadores envolvidos em meio às possíveis "falhas" do mercado concorrencial, ao passo que possíveis esforços na redistribuição da renda almejariam um acesso incondicional a bens e serviços públicos na quantidade e qualidade demandados pelo corpo social. A redistribuição intentaria forjar uma sociedade assentada nos princípios da igualdade e reciprocidade, valores presentes no desenho do sistema de proteção brasileiro introduzido com a Constituição de 1988. No entanto, como já adiantara o palestrante: "Não adianta ser o revolucionário com suas ideias doidas!"

0 mantra entoado pelo palestrante se alinha com as tradicionais teorias da competitividade econômica, posto que a determinação da renda, em situação de concorrência perfeita, é entendida como fruto do esforço de indivíduos que navegam num "mar de oportunidades" econômicas que premiam a produtividade e a poupança.

Para os adolescentes dos programas sociais, cursos profissionalizantes eram ofertados em acordo com a demanda de mão de obra do mercado interno de sua cidade. 0 aviltante mercado da construção civil brasileiro parecia ser a principal porta de entrada para o mercado de trabalho para estes jovens numa cidade que, à época, importava mão de obra nesta área. Pedreiros, Carpinteiros, Eletricistas, Mecânicos Automotivos, etc. eram os cursos que apresentavam um maior número de vagas - cursos que não necessariamente iam ao encontro dos interesses dos jovens. Muitas vezes, eles se queixavam de não conseguir alcançar o alfabetismo digital, posto que os cursos na área de informática eram destinados e disputados por aqueles que tinham um maior nível de educação formal, geralmente a partir do $7^{\circ}$ ano $\left(6^{\mathrm{a}}\right.$ série do Ensino Fundamental). Outras habilidades, como o interesse por artes de uma forma geral, além de escassos cursos disponíveis, também exigiam um maior nível de escolaridade.

Este critério, inclusive, era muitas vezes utilizado na orientação aos adolescentes porque servia para demonstrar a necessidade de continuidade dos estudos. Aparecia, nestes momentos, a normatividade de um futuro que deveria ser planejado prospectivamente, encadeando o nível de escolarização com a ampliação de possibilidades de inserção no mercado profissional. 0 que de fato habitava a rotina dos es- paços formais de educação como efetivo funcionamento da maquinaria escolar raramente entrava em questão, pois o principal era ter um certificado de conclusão de determinada série; um papel, a "senha" que permitisse sair de um espaço e entrar noutro nos resquícios de uma lógica disciplinar adaptada aos mecanismos de segurança ${ }^{1}$. Adapta-se, assim, a velha técnica disciplinar de controle sobre os movimentos do corpo dentro de um espaço fechado às exigências das técnicas securitárias que atuam na produção de territórios existenciais "ao ar livre", num processo modulatório que se encarna em estilos de vida "vencedores".

Já no que dizia respeito aos profissionais da cada vez mais ameaçada categoria dos servidores públicos, o palestrante alcançava àqueles que investiam o seu tempo fora do seu atual vínculo com o estudo para outros concursos - geralmente os de nível federal -, motivando-os a perseverar, a acreditar que a hora certa há de chegar para aqueles que se preparam corretamente. Sem exceção, a todos se vendia a ilusão de que é possível vencer.

\section{O GOVERNO DA POBREZA PELO MERCADO CAPITA- LISTA: FINANCEIRIZAÇÂOO DAS POLITICAS SOCIAIS}

Segundo Foucault (2008b), é relativamente comum entendermos as políticas sociais como tendo como objetivo principal uma compensação a processos econômicos selvagens que vão induzir efeitos de desigualdade, de produção e acumulação de riquezas por si mesmos. Nessa direção, pautadas geralmente numa lógica de transferência de renda, tais políticas promoveriam, proporcionalmente ao crescimento da economia, uma série de esforços de compensação aos efeitos econômicos do modo de produção capitalista.

Todavia, o que o pensador francês expõe em seu curso "Nascimento da Biopolítica" é que, no neoliberalismo (Foucault, 2008b, p. 198), "só há uma política social verdadeira e fundamental: o crescimento econômico". Sendo assim, não se trata de uma compensação de uma série de efeitos de desigualdades, mas, sim, de fazer das políticas sociais um conjunto de práticas que possa gerar crescimento econômico. É este último que deve permitir que todos alcancem um nível de renda mínimo que lhes possibilite os seguros individuais, o acesso à propriedade privada, à capitalização individual ou familiar, com as quais poderão absorver os riscos imanentes no mercado capitalista.

Nesse sentido, Lavinas (2015) aponta que o século XXI institucionaliza a articulação entre política econômica e política social na América Latina a partir da implementação das sociedades de consumo de massa - especificamente o Brasil, que alcançou o feito histórico de incorporar de forma inconteste dezenas de milhões de indivíduos ao mercado de 


\section{W'INTERACÃO EM ET PSICOLOGIA}

consumo na primeira década dos anos 2000 , sem necessariamente equalizar oportunidades e diminuir as profundas desigualdades características de nosso legado histórico. 0 saldo mais positivo dessa estratégia social desenvolvimentista foi o de praticamente "universalizar o acesso a determinados bens de consumo duráveis ao longo da curva de distribuição de renda, contribuindo, portanto, para o aquecimento da demanda doméstica e fazendo do consumo das famílias o motor do crescimento econômico recente" (Lavinas, 2015, p. 3).

Dessa feita, se se trata de governar a pobreza tendo como mecanismo de validação o crescimento econômico, pode-se entender que as práticas de enfrentamento da pobreza, dentro de um modelo econômico neoliberal capitalista, se limitarão a combater os efeitos, mas não esta ou aquela causa da pobreza. O combate se dá prioritariamente sob a forma de benefícios àqueles corpos que se encontram abaixo de certo nível de renda capaz de proporcionar às pessoas um consumo suficiente, dificultando assim a fruição econômica. Benefícios estes de uma razão governamental que trabalha incessantemente para que o mercado (alçado à condição de princípio de verificabilidade das práticas de governo) possa ter sua "natureza" concorrencial assegurada via manutenção de cada um numa posição de desigualdade diferencial com todos os outros e engendrando, por desdobramento, todo um modo de subjetivação espraiado pelo corpo social, que deve assistir somente e momentaneamente os que se encontram abaixo do seu limiar de se constituírem como "empresas" (Foucault, 2008b).

Gilles Deleuze, ao versar sobre as sociedades de controle antevia, em meio a uma série de dispositivos de controle que se dão ao ar livre, a empresa como "uma alma, um gás" (Deleuze, 1992, p. 221). Para ele, a forma-empresa "se esforça mais profundamente em impor uma modulação para cada salário, num estado de perpétua metaestabilidade, que passa por desafios, concursos e colóquios extremamente cômicos" (Deleuze, 1992, p. 221). A empresa postula a formação permanente, o funcionário do mês, o controle contínuo como parte de seus constantes processos de modulação. Nas sociedades de controle, onde a forma-empresa torna-se emblemática, "nunca se termina nada, a empresa, a formação, o serviço sendo os estados metaestáveis e coexistentes de uma mesma modulação, como que de um deformador universal" (Deleuze, 1992, pp. 221-22). A esta nova configuração, corresponde o controle contínuo e a comunicação instantânea, modulando as formas de produção de sanções, educação, saúde, etc. De acordo com Deleuze (1992), o homem-empresa das sociedades de controle funciona num feixe contínuo modulado por um capital que se dirige para a "compra de produtos acabados, ou monta peças destacadas. O que ele quer vender são serviços, e o que quer comprar são ações. Já não é um capitalismo dirigido para a produção, mas para o produto, isto é, para a venda ou para o mercado" (p. 223-24).

O homem-empresa não é o homem confinado do regime disciplinar, mas sim o homem (potencialmente) endividado em meio aos investimentos em si mesmo como próprio capital. Na nossa atual conjuntura, Lavinas (2015) aponta que a classe C, com renda familiar per capita de até $\mathrm{R} \$ 1.184,00$ mensais em 2015 , equivale à metade da população brasileira e é detentora de $58 \%$ dos empréstimos nacionais. Essa classe destina $65 \%$ de sua renda ao pagamento de serviços e $35 \%$ à compra de produtos, quando esse percentual era inverso dez anos antes. Sendo assim, com a inclusão social via consumo pela estratégia desenvolvimentista da última década, a renda da maioria da população brasileira foi sendo tomada por níveis crescentes de endividamento, por tributos indiretos massacrantes e pelo predomínio na aquisição dos direitos de cidadania (saúde, educação, segurança, transporte, etc.) no mercado privado. Segundo Lavinas (2013), nos primeiros meses de 2015 , o endividamento das famílias brasileiras comprometia $48 \%$ de sua renda, contra $22 \%$ no início de 2006. Ressalta-se ainda que isso não seria um grande problema se, em meio à recessão econômica, o governo não resolvesse modificar a regra de acesso ao seguro-desemprego, cortar e reduzir pensões por morte, e se o sistema tributário não ficasse, pela sua estrutura regressiva que incide fortemente sobre o consumo, com pouco mais da metade da renda bruta das famílias que vivem com menos de dois salários mínimos mensais.

O crescimento econômico, portanto, não se reflete necessariamente na melhoria social, já que, ao invés da ampliação na oferta de bens públicos que equalizariam oportunidades e bem-estar, o que se experimenta é a mercantilização de todas as dimensões da vida sob a supremacia dos seguros privados e créditos para todo tipo de infortúnios. Nesse modo de governo da vida, a inclusão financeira se torna o novo mantra, reconfigurando o lugar social de cada indivíduo a partir da multiplicação dos empréstimos pessoais como um dos principais eixos da dinâmica de securitização. Segundo Lavinas (2015, p. 19):

A finança, na verdade, é, na atualidade, consubstancial a todo tipo de produção de bens e provisão de serviços. Como bem assinala Lazzarato (2012), ela se apropria, através de múltiplos e sofisticados mecanismos de endividamento, da esfera do bem estar social levando à privatização de seus serviços e transformando a política social num setor antes voltado para a acumulação e o lucro das empresas privadas, notadamente financeiras, do que para sanar iniquidades e tornar as sociedades mais igualitárias. 
Esse amplo processo de endividamento ganha contornos não só financeiros, mas também morais, ao passo que deve permitir programar o tempo e os comportamentos do homem-empresa, posto que as obrigações da dívida permitem prever, calcular, medir e estabelecer equivalências entre os comportamentos atuais e futuros. É preciso pisar firme, mesmo que endividado e em terreno não muito seguro, e planejar com cuidado a sequência de passos até o sucesso.

Nessa moratória ilimitada, produz-se uma série de modulações subjetivas a partir do desdobramento do modelo investimento-custo-lucro para um modelo de existência. Neste modelo, segundo Souza (2012), as atividades socioeducativas, que compõem o rol de exigências das ações propostas pelos operadores do SUAS - seja no trabalho com crianças, adolescentes, adultos ou idosos - surgem como modos de fazer e solucionar em todos os espaços da política pública de assistência social. Logo, todo e qualquer investimento educacional ou, ainda, sócio-educacional, pode ser visto sob o prisma de uma economia política do desejo que tende a esquadrinhar a vida em dispositivos dos mais variados nomes - disciplina, capacidade de concentração, pensamento prospectivo, projetos de vida, etc. - , confeccionados a partir de um modo de subjetivação afeito às práticas governamentais de nossa atualidade. Em acordo com Lazzarato (2011), para que isso ocorra, é preciso pôr em funcionamento, simultaneamente, as ancestrais técnicas disciplinares e as mais recentes técnicas de segurança. As primeiras - vigilância, sanção, exame, exclusão - são reestruturadas e adaptadas às novas funções que requerem as segundas - incitação, mobilização à empregabilidade através da modulação e da individualização, e diferenciação das políticas sociais. A ativação destas tecnologias disciplinares e de segurança suscita, simultaneamente, uma inflação de atos jurídicos e de atos legais, bem como a proliferação de normas e regulamentos provenientes do Estado e das instituições de regulação do mercado de emprego. 0 mercado e a concorrência são, portanto, o resultado de uma construção que necessita de uma multiplicidade de intervenções, especialmente do Estado, para existir e funcionar. Para poder "deixar andar", é preciso intervir não sobre o mercado, mas pelo mercado - intervir simultaneamente e o máximo possível sobre as condições econômicas e sobre as condições não diretamente econômicas de funcionamento do mercado e da concorrência.

\section{VULNERABILIDADE E RISCO SOCIAL COMO “ATIVOS" DO “EMPREENDEDORISMO DE SI MESMO"}

Vulneráveis ou não, a palestra expõe um modo de habitar o nosso presente, de fazermos de nós mesmos partícipes de um modo de subjetivação capitalístico que produz a todos nós como efeitos e instrumentos de uma lógica concorrencial de mercado no qual comumente se mensura a liberdade pela amplitude das nossas possíveis escolhas de consumo. Aos jovens e aos profissionais, ambos ansiosos por oportunidades que ampliem sua liberdade de consumo/escolha para além de suas vulnerabilidades (sociais ou não), cabe preparo, motivação, planejamento, etc. Cabe toda uma modulação da produção desejante em limites "possíveis" e articuláveis à moldura do sistema de produção capitalista atual que nos produz contornos nos quais se pode e deve investir para alcançar um futuro promissor.

Em acordo com Maciel Júnior (2005), nossas escolhas possibilitam cada vez menos questionamentos e hesitações que apontariam para a existência de produção subjetiva singular, posto que se dão entre possíveis já determinados. 0 futuro aparece, portanto, sob a forma de um projeto que venha garantir a melhoria ou continuidade de uma maneira de ser estabelecida dentro dos limites impostos pelas diversas instâncias encarregadas de ordenar, normatizar e produzir comportamentos e subjetividades pré-moduladas em meio às quais nos produzimos. Nessa lógica, parece haver muito pouco tempo ou espaço de exploração de potências outras fora daquilo que se configura como aventuras criativas a serem consumidas, de preferência, também como investimentos em humanidade capitalizável. Para Lazzarato:

a capitalização é uma das técnicas que devem contribuir para transformar o trabalhador em "capital humano", aquele que garante por si só a formação, o crescimento, a acumulação, a melhora e a valorização de "si" enquanto "capital" por meio da gestão de todas as suas relações, suas escolhas, suas condutas segundo a lógica da relação custos/investimentos e segundo a lei da oferta e da procura. A capitalização deve contribuir para fazer dele "uma espécie de empresa permanente e múltipla". o que agora é exigido dos indivíduos não é a garantia da produtividade do trabalho, mas a rentabilidade de um capital (de seu próprio capital, de um capital inseparável de sua própria pessoa). 0 trabalhador não é mais um simples fator de produção, o indivíduo não é, estritamente falando, uma força de trabalho, mas um capital-competência, uma "máquina de competências", que vai de par com um "estilo de vida, um modo de vida", uma escolha moral, uma "forma de relação do indivíduo consigo mesmo, com o tempo, com o seu entorno, com o futuro, com o grupo, com a família". (Lazzarato, 2011, p.31-32, grifo nosso)

Nestes tempos, é preciso $\mathrm{C}-\mathrm{H}-\mathrm{A}$. O C-H-A da persistência para um futuro falaciosamente "brilhante" que se gesta decantando potencialidades governáveis.

Atitude que não é abuso, mas dócil, eficiente e útil; Habilidade que seja tecnicamente neutra, precisa e de preferência com obsolescência programada; e Conhecimento que não produza problematização, mas soluções criativas que ampli- 


\section{H* INTERACÃO EM 4. PSICOLOGIA}

em a empregabilidade. Este é o mantra do empresário que tem como substrato calculável dos seus negócios algo muito próximo, talvez a fonte mais próxima que possa existir - si mesmo. É nesse cálculo que se fabrica o vencedor a partir de uma multiplicidade de investimentos de todos os seus recursos (na formação, na aparência, na mobilidade, na afetividade, na cultura, no lazer, etc.) que se deve fazer para otimizar as suas performances dentro de um espaço concorrencial no qual deve se situar de forma privatizada e intimista.

Ao tornar o humano capitalizável, promove-se uma identificação entre individualização e exploração, já que o "empresário de si mesmo" é, igualmente, patrão e escravo de si mesmo, capitalista e proletário, sujeito de enunciação e sujeito do enunciado. Como um bom exemplo disso, podemos destacar a flexibilização do seguro social através da criação da figura jurídica do Microempreendedor Individual (MEI), ou ainda Empreendedor Individual (EI). Esta figura formaliza vínculos com a seguridade social ao criar uma nova e mais baixa faixa de tributação do Brasil ( $5 \%$ contra $20 \%$ sobre o salário mínimo vigente), isenta de vários tributos federais e com cobertura previdenciária e concessão de crédito a juros módicos. Com o status de pequenos empresários, trabalhadores autônomos que atuam em cerca de 500 ocupações (dentre elas ambulantes, cabeleireiro, manicure, esteticista, costureira, artesão, borracheiro, sapateiro, mecânico, etc.) podem contratar até um funcionário pagando salário mínimo ou piso da categoria com menor carga tributária (Salgado, 2012).

Figura que nos últimos anos vem sendo associada a noções de desenvolvimento, prosperidade e cidadania em meio a um processo de transferência para o indivíduo da responsabilidade estatal e/ou macroeconômica de acesso ao trabalho, "ter uma boa empregabilidade" vem gradativamente deixando de ser sentença usada para referir mercados ou profissões e passa a aludir aos próprios indivíduos.

Para além das garantias de cidadania ao se formalizarem, com o benefício de acesso ao crédito, o estímulo ao empreendedorismo contempla ainda o interesse de instituições financeiras que, através da venda de financiamentos e empréstimos, passa a atingir um novo e promissor público estimado em cerca de 10,8 milhões de trabalhadores que não contavam com proteção previdenciária segundo a Pesquisa Nacional de Amostra por Domicílio (PNAD) de 2009 (apud Salgado, 2012). Com essa justificativa, o governo federal aprovou o subsídio ao "crédito barato" com taxas de juros a partir de $8 \%$ ao ano não apenas através de agências financeiras estatais como Banco Nacional de Desenvolvimento Econômico e Social (BNDES) ou Banco do Brasil, mas também de bancos particulares como o Santander e o Bradesco. Sendo assim, ao passo que a garantia de acesso ao crédito torna-se fator de distinção social e cidadania, por outra via, o governo também presta a assistência aos bancos (Salgado, 2012).

Ao promover uma progressiva inserção de trabalhadores nos valores e práticas do mundo empresarial, o MEl é a figura que simboliza a demonstração de possível vitória do sujeito que "vem de baixo". Daqueles corpos que, a partir do correto investimento em seu capital humano, superaram as dificuldades da vida através de seus $\mathrm{C}$-H-As. Nessa lógica de vencedores, aqueles que não ousam se arriscar passam majoritariamente a serem vistos como perdedores. Permanece pobre, portanto, quem despreza sua capacidade empresarial e não consegue enxergar as inúmeras oportunidades de negócios.

Assim, as subjetividades empreendedoras ganham, nas caracterizações dos Els, interpretações sempre positivas (energia, flexibilidade, autonomia), deixando ao campo do não-dito, por exemplo, as dificuldades de ser seu próprio chefe, de fazer seus próprios horários e de não ter auxílio alheio na tomada de decisões. E assim se constrói a imagem de um indivíduo naturalmente satisfeito com e adequado às novas demandas do mercado de trabalho, um indivíduo cujo "espírito empreendedor" acompanha o novo espírito do capitalismo (Salgado, 2012, p. 136, grifo nosso).

Na conjunção entre os esforços individuais dessa figura e uma política de governo que intenta legalizar e conferir seguridade aos trabalhadores informais, o Estado encontra uma alternativa viável não só para o desemprego, mas também para a miséria que aflige parte de sua população. Acreditando no poder dessa figura, o Serviço Brasileiro de Apoio às Micro e Pequenas Empresas (SEBRAE), em parceria com o Ministério do Desenvolvimento Social (MDS), lançou em 2012 a cartilha "O empreendedor individual e o Programa Bolsa Família - Uma Oportunidade para Crescer". Destinada aos beneficiários do programa social, o material se esforça em demonstrar como, através do MEl, essas pessoas podem encontrar uma oportunidade única de crescimento e inclusão produtiva, saindo por fim da condição de dependentes do governo e tornando-se empresários (Salgado, 2012).

Assim, ao enfatizar a proliferação de discursos de que qualquer um pode e deve se tornar empreendedor, o próprio MDS aponta que deixar de precisar do Programa Bolsa Família $(\mathrm{PBF})^{2}$ é progredir econômica e socialmente. Propaga-se, assim, mesmo que indiretamente, a ideia de que aqueles que permanecem sem trabalho ou renda o fazem porque querem, porque seriam desajustados de uma norma que preconiza a disposição a riscos financeiros, psicológicos e sociais inerentes à atividade empresarial reguladora da vida. Visando o crescimento, o lucro, o sucesso e resgatando as noções de 


\section{WIIITERACÃO EM ET. PSICOLOGIA}

individualidade e flexibilidade em conjunto com o conceito de empregabilidade, a norma empresarial preconiza cada vez mais a necessidade de indivíduos proativos, criativos e empreendedores.

Como uma grande resposta aos problemas sociais, essa cultura em franca institucionalização no Brasil naturaliza o empreendedorismo como próprio da espécie humana, fabricando uma panaceia para a construção de sustentabilidade e justiça social num processo que funde cidadania e consumo. Sepultada a possibilidade de discutir caminhos alternativos ao capitalismo, trata-se então de capilarizar até o nível mais ínfimo os valores empresariais submetidos à dinâmica concorrencial. Assim, conhecimentos, habilidades e atitudes se modulam enquanto um arsenal de condutas que podem e devem ser desenvolvidas em relação às possibilidades flutuantes de consumo de autonomia, cidadania, escolha, autenticidade e liberdade, vistas cada vez mais individualizadas e apartadas de um contexto político mais amplo. Produzse, assim, uma ética do sujeito emergente que modula sua existência em função das "oportunidades" de que o seu meio dispõe.

Meio que, devido a sua imanência nas flutuações do mercado, se apresenta como incerto, produzindo corpos com angústias e ansiedades familiares à incerteza, jogados à sorte de projetos de vida majoritariamente curtos, intermitentes e desencaixados, cuja gestão escapa à responsabilidade de instituições mais sólidas e recai sobre os seus próprios ombros.

$O$ vencedor, aquele que participa ativamente do jogo concorrencial, que desenvolve o trinômio do C-H-A como convém às normativas do momento, é visto como capaz de fazer prosperar não só sua vida, mas a de todos ao seu redor. Sendo assim, ao promover uma sinonímia entre desenvolvimento social e empreendedorismo, admite-se a necessidade do fomento da cultura empresarial entre a nossa população como um caminho fundamental de combate ao desemprego e a pobreza em uma governamentalidade neoliberal. De acordo com Foucault (2008a), "o que propus chamar de governamentalidade, isto é, a maneira como se conduz a conduta dos homens, não é mais que uma proposta de grade de análise para essas relações de poder" (p. 258). Para os jovens vulneráveis que precisam aprender a desenvolver corretamente seu $\mathrm{C}-\mathrm{H}$ A, sua inferioridade é frequentemente entendida como fracasso, como falta de vigor competitivo ou por deficiências no exercício de aprimoramento do seu capital humano. Aos "excluídos", para além das deficiências das políticas de Estado, entende-se que faltou dedicação à educação, a aquisição da ética de trabalho, a submissão à disciplina, etc.

É nesse sentido que questionamos como as políticas de assistência em nossa sociedade, para conter os "problemas sociais" inventados pela lógica do sistema produtivo, se pautam pela criação de mecanismos tutelares e de contenção daquilo que se pode chamar de "anormalidades" sociais. Segundo Lazzarato (2011), não se pode entender a proteção social como uma simples proteção contra os riscos sociais, mas também como uma técnica de governo de um modo de vida ao qual ela assujeita os indivíduos. Qualquer pessoa ou grupo que não queira aceitar esse modo de vida se encontra marginalizado.

Desse ponto de vista, as práticas de assistência contemporâneas investidas pelo Estado, ou em parceria público-privada, não deixam de ser tecnologias de controle da vida, de regulação social, cujo funcionamento na atualidade pode ser visto desde os cuidados com a infância em perigo e com os adolescentes em conflito com a lei, até o abrigamento de moradores de rua e acompanhamento das condicionalidades das famílias beneficiárias do bolsa família. Ou seja, tais práticas podem ser pensadas como componentes de uma tecnologia biopolítica, que consiste em regular o cotidiano, sobrecodificando e descodificando os acontecimentos e gerindo os modos de vida pela utilização cada vez maior dos processos de normalização e dos discursos da segurança.

A biopolítica, que tem ao seu dispor diversos processos e conhecimentos (relatórios, enquetes, pesquisas e bancos de informações que disponibilizam dados cada vez mais meticulosos), gesta-se no entrecruzamento de exercícios de poderes que acabam por produzir, conhecer e explorar o que se passa na "cabeça das pessoas", a fim de dirigi-las e que tem como principal efeito e instrumento a produção de sujeitos através de regras previamente perpetradas de conduta. Regras que conjugam um sem número de técnicas, táticas, estratégias de saber-poder no nível limitado em que se inscrevem e que encadeando-se entre si, invocando-se e se propagando, encontrando em outras partes apoio e condição, esboçam finalmente dispositivos de conjunto como o POP que articulava intervenções de psicólogos, assistentes sociais e as receitas do palestrante.

Dessa feita, podemos problematizar as questões que compõem atualmente o SUAS como intrinsecamente atravessadas por uma produção social da existência fortemente pautada pelo modo de produção capitalista neoliberal. Para Foucault (2008a), esta se caracteriza hegemonicamente pela produção e organização da liberdade. Sendo assim, a segurança, ou melhor, poderíamos falar em seguridade social, aparece então como o princípio de cálculo desse custo de fabricação da liberdade. 0 que está em jogo é justamente o esforço de uma série de práticas que fazem a potência inventiva da vida se contrariar e neutralizar, funcionando assim como remédio e combustível para a sobrevivência de uma economia política pautada na liberdade de fluxos econô- 


\section{W'INTERACÃO EM ET. PSICOLOGIA}

micos.

É em meio a isso que podemos e devemos pensar a atuação no SUAS. Longe de tomar o pensador francês como uma verdade já dada, posto que afinal de contas falava de tecnologias de governamentalização de Estados europeus que se formaram de maneiras completamente diferentes da nossa, tendo inclusive implementado o estado de bem-estar social (algo que, como nos apontam Santos (1987) e Lobato (2016), a nossa configuração política desenvolveu de forma fragmentada e desigual), acreditamos que suas ferramentas conceituais nos são úteis na medida em que nos permitem empreender uma analítica do poder utilizando um modo de pensar que não remeta necessariamente à lógica da inclusão de um sem número de vidas faltosas num mecanismo Estatal que os oprime.

A temática do poder como exercício microfísico que nos atravessa e seus dispositivos correlatos nos ajuda a entender os perigos inerentes à temática da proteção dos vulneráveis que se faz ao afirmar potencialidades no mundo do trabalho, do planejamento da vida saudável, no futuro normatizado, no cálculo prescritivo de vida, etc. Proteção que facilmente pode se ressentir quando colocada à prova em sua opacidade à medida que funciona, ao mesmo tempo, como efeito e instrumento de atualização e propagação dos dispositivos de poder que a constrangem com elementos que fazem da proteção algo apartado das potências que diferem e se recusam a serem potencializadas em caminhos da busca por tranquilidade dentro dos parâmetros de bem-estar consolidados de vida a ser vivida de forma apaziguada. Esperanças, medos, violências, vulnerabilidades, riscos, direitos, deveres, etc. usados a favor da produção de uma vida segura.

É a delegação de poder de tutela sobre a vida, que "em nome do cuidado", "em nome da justiça" e "em nome de minimizar riscos e vulnerabilidades" acaba por desqualificar ou desconsiderar modos autônomos de expressões do ser denominando-os de doenças, desequilíbrios, síndromes e vulnerabilidades e/ou riscos. Nessa direção, educação e a profissionalização dos indivíduos tornam-se meios primordiais para produzir todo um conjunto de controles e decisões que tem por objetivo integrar a atividade humana como constitutiva de relações efetivamente úteis e dóceis à ordem social. É preciso investir - via equipes multidisciplinares e transferências de renda - no fomento de conhecimentos, habilidades e atitudes como "ativos" para a responsabilidade diante dos riscos sociais.

\section{HABITAR A AGONÍSTICA DO PÚBLICO NAS POLÍTI- CAS PÚBLICAS}

Intentamos afirmar, ao longo da confecção de todo este escrito, relações possíveis entre vidas vulnerabilizadas e seus supostos encaminhamentos. Aos que o SUAS elenca como vulneráveis, se prefigura rapidamente lugares vencedores os quais são tomados como norte numa lógica de governamentalidade neoliberal. Seja ao nível preventivo, seja diante de um risco social já instaurado, há modos de fazer que se afirmam fortalecendo vínculos, diminuindo exposições ao risco ou aprimorando respostas "qualificadas" a manejá-los como socialmente se espera. Na letra fria da lei e nas normas que sub-repticiamente se impõem, monumentos são erguidos "em nome de..." e passam a regular a existência nos jogos com a vida. Jogos que majoritariamente esconjuram o desassossego em ciclos de pobrezas a serem combatidos; em faltas a serem sanadas na obsolescência programada das soluções dos especialistas da vez.

No entanto, entre vulneráveis e vencedores, algo se passa para além desses prescritos. Algo que pode precariamente abrir veios, vales e rugas. Veredas em vidas que se entendem ser-tão faltosas e vulneráveis. Entre vidas que pulsam e deixam rastros de suas forças, ainda apostamos na habitação destas políticas de governo do vivo em sua possibilidade de invenção do público. Segundo Kastrup (2007), invenção que se faz com a memória, com o encontro com as relíquias, através da composição e recomposição permanente com os cacos de histórias, com as raridades, as singularidades das vidas. O resultado deste encontro é sempre imprevisível e demanda um vagar, uma paciência, posto que não opera sob o signo da instantaneidade que preconiza soluções rápidas e criativas para os problemas que nos acometem. Resgatando a etimologia da palavra latina invenire, Kastrup (2007) afırma que a invenção implica "um trabalho com restos, uma preparação que ocorre no avesso dos planos das formas visíveis. Ela é uma prática de tateio, de experimentação, e é nessa experimentação que se dá o choque, mais ou menos inesperado, com a matéria" (p.27).

Em nosso tempo, no qual por vezes nos perguntamos o que ainda nos faz lutar por políticas públicas, talvez encontremos nessa aposta da invenção de público possíveis caminhos para a nossa militante insistência. Militância que não se ressente com o fato de que as coisas não são como propunha o passado para o futuro, mas que em meio aos prescritos "em nome de...", os atravessa e, ao promover distanciamentos estratégicos, desloca olhares e fazeres em meio a problematizações acerca dos perigos aos quais emergimos em nosso contemporâneo.

É nessa atitude, em meio ao inusitado dos encontros intensivos, de que emergem e provêm as interpelações a nossas escritas, pesquisas e militâncias. Com que forças nos agenciamos em nossos modos cotidianos de fazer política pública em meio a tempos tão duros? Como dizer da experi- 


\section{MI* INTERACÃO EM LF PSICOLOGIA}

ência de retrocesso e desmonte absurdo no campo das políticas públicas? Como insistir e persistir na aposta de produzir frestas oxigenantes em meio aos desmontes e desmandos vigentes no caráter público das políticas públicas? Como e para que ainda lutarmos por Políticas Públicas? Como pensar uma política onde caibam os processos de devires complexos, singulares e paradoxais, que atravessam nossas vidas?

Travar este combate nas políticas assistenciais vigentes requer um exercício constante de problematizar as significações hegemônicas que segmentam a expressão dos verbos da vida em identificações que fixam, paralisam e capturam os processos de subjetivação entre as nossas submissões e sujeições aos paradigmas indispensáveis à conservação do estado de coisas e ao bom funcionamento social. É neste regime que nos constituímos e travamos nossos combates; fazendo com e em meio a eles um novo uso da liberdade e de nós mesmos.

Habitar os desassossegos e sua violência na experiência das políticas públicas não é trivial! Implica um vagar que teça estratégias de esquiva e combate aos imperativos assépticos às forças de afetação e afirme os problemas produzidos nos inúmeros encontros. Implica uma delicadeza para espreitar na brutalidade dos fatos o que é índice intensivo de movimento-desvio. Implica uma atenção às microfissuras e potência das vozes, corpos, vidas combalidas, brutalizadas que insistem em não se deixar vulnerabilizar.

É talvez na aposta da transmutação da agonia para a agonística que outra habitação do exercício dessa política de Estado pode ganhar outras densidades nos modos nos quais a integralidade da vida se dá em suas mais variadas formas e intensidades. Nesse exercício, político por definição, a capacidade de afirmação da diferença como substantiva se vê fortalecida na justa medida que os parâmetros de aproximação, generalização e enfraquecimento da disparidade são esboroados.

A passagem da agonia para a agonística afirma uma arte da luta em meio às perenes batalhas que insistentemente travamos no exercício de produção de liberdade. Agonística que proclama que não há descanso possível; não há vitória final ou representação possível na insistência de gestação da liberdade. Nesse sentido, sustentar o combate entre díspares seria então uma necessidade de primeira ordem, uma vitória a ser conquistada sobre os apaziguamentos que se quer imprimir à vida.

Por que agonística? Por que arte do combate? Porque não há garantias e horizonte de tranquilidade nos exercícios de sermos livres. Trata-se, portanto, de insistir e persistir em pensar em meio a nossa experiência de um momento político de retrocesso na lógica da garantia dos direitos, em que, por vezes, em momentos de fraqueza, parece ser impossível con- tinuar. Sustentar o combate torna-se então ascese necessária, uma vitória a ser conquistada sobre a tristeza, a fraqueza, o ressentimento e o silenciamento (ou seu contraponto - o imperativo de falatório interminável e vazio) que nos pregam. Como afirma Foucault (1995), a propósito da agonística,

a relação de poder e a insubmissão da liberdade não podem, então, ser separadas. O problema central do poder não é o da "servidão voluntária" (como poderíamos desejar ser escravos?): no centro da relação de poder, "provocando-a incessantemente, encontra-se a recalcitrância do querer e a intransigência da liberdade. Mais do que um "antagonismo essencial", seria melhor falar de um "agonismo" - de uma relação que é, ao mesmo tempo, de incitação recíproca e de luta; trata-se menos de uma oposição termo a termo que os bloqueia um em face do outro, e mais de uma provocação permanente (Foucault, 1995, p. 244-245).

Combate que, em oposição ao alinhamento com o que já se conhece, afirma o risco como constitutivo de si. Não o risco tal qual pensado pelas lógicas biopolíticas de gestão do vivo; não o risco adjetivado a partir das formas às quais se pensa que a vida mereça ser vivida, mas o risco do que não tem sossego e nunca terá. 0 risco que, mesmo sem que o saibamos, nos faz calar, nos faz perder o sono e, paradoxalmente, nos instiga a continuar "em meio a..." e para além dos modelos pré-moldados. Riscos que, ao se intensificarem, podem promover como efeito a constituição de um plano de consistência dessas forças que nos assediam, dos gritos do intolerável e suas múltiplas vozes que o habitam por entre ruelas, cheiros, encruzilhadas e cacos de estórias. Cacos que servem para cortar, irromper outros fluxos que encarnem nos corpos as marcas de encontros intensivos que se esboçam em nossos fazeres. E nesta encarnação promovam um quantum de consistência na habitação de uma política de Estado ao atiçar o que pode haver de caráter público no cotidiano de suas práticas. Caráter este entendido como aquilo que produz desvios nos constrangimentos já instituídos e inclui a usinagem da diferença substantiva do/no território. Talvez em nosso presente, essa seja a possibilidade mais digna nos encontros com o outro - a da invenção de outros modos de estar nos verbos da vida que expandam os índices de liberdades e indiquem a produção de uma outra estética da existência.

É preciso, portanto, estar à espreita das desestabilizações que se gestam na repetição de falatórios intermináveis de prescrições de como viver cheias de certezas e insolências individualizadoras. Atentos aos desassossegos que nos invadem e atualizam os limites estreitos dos nossos saberes e que, por muitas vezes, nos obrigam a falar o menos possível para que algo de diferente possa ser efetivamente dito e escutado. E, nos intervalos deste exercício de produção de pú- 


\section{H NTERAC̄OAEM ET. PSICOLOGIA}

blico numa política de Estado, mesmo quando tomados de cansaço, apostemos no esforço de arriscar-se sem garantia de sucesso, vitória ou recomeço.

Aposta esta que se esquiva do peso da utilidade fria de uma vida calculada entre direitos e deveres e se põe a prova nos embates que mais do que pastorear existências, talvez como nos aponte Ferreira (2015), entende a política como não se restringindo à conquista de direitos, mas a atravessando. Aposta que almeja promover o cuidado no desassossego e atualiza a pergunta sempre pertinente do que estamos fazendo de nós mesmos.

\section{CONTRIBUIÇÃO DE CADA AUTOR}

Ambos os autores são os responsáveis pela conceitualização, investigação e redação final do artigo. Sendo que o segundo autor realizou a supervisão da pesquisa e contribuiu na redação - revisão e edição. Já o primeiro autor iniciou a investigação e realizou a redação - preparação do manuscrito original, revisão e edição.

\section{DECLARAÇÃO DE CONFLITOS DE INTERESSE}

Os autores declaram que não há conflitos de interesse no manuscrito submetido.

\section{FINANCIAMENTO}

O artigo é um desdobramento da pesquisa de doutorado do primeiro autor, sendo esta financiada pelo Centro de Aperfeiçoamento de Pessoal do Ensino Superior (CAPES) sob a orientação do segundo autor.

\section{REFERÊNCIAS}

Deleuze, G. (1992). Conversações: 1972-1990. Rio de Janeiro: Ed. 34.
Ferreira, M. S. (2015). A intolerância se manifesta de muitas formas e mata. Entrevistado por E. Araujo e editada por S. Souza.

Foucault, M. (1995). O sujeito e o poder. Em H. Dreyfus \& P. Rabinow. Michel Foucault, uma trajetória filosófica: Para além do estruturalismo e da hermenêutica. (V. P. Carrero, trad.). Rio de Janeiro: Forense Universitária.

Foucault, M. (1997). Vigiar e punir: Nascimento da prisão (16. Ed). Petrópolis: Vozes.

Foucault, M. (2008a). Segurança, território e população: Curso no Collége de France (1977-1978). São Paulo: Martins Fontes.

Foucault, M. (2008b). Nascimento da biopolítica: Curso no Collége de France (1978-1979). São Paulo: Martins Fontes.

Gama, B. C. (2017). Insistências entre o vulnerável e o vencedor no governo do vivo: Ensaios na política pública de assistência social. Tese (Doutorado em Psicologia) Instituto de Psicologia, Universidade Federal Fluminense - UFF - Niterói, RJ, Brasil.

Kastrup, V. (2007). A invenção de si e do mundo. Uma introdução do tempo e do coletivo no estudo da cognição. Belo Horizonte: Autêntica Editora.

Lavinas, L. (2013). Notas sobre os desafios da redistribuição no Brasil. Em A. Fonseca \& E. Fagnani (Orgs.). Políticas sociais, desenvolvimento e cidadania. São Paulo: Fundação Perseu Abramo. Tomo 1, 99-143.

Lavinas, L. (2015). A financeirização da política social: 0 caso brasileiro. Em Forthcoming at Politika, (2). Rio de Janeiro, Fundação João Mangabeira em colaboração com Humboldt-Viadrina Governance Platform, 35-51.

Lazzarato, M. (2011). O governo das desigualdades: Crítica da insegurança neoliberal. São Carlos: EdUFSCar.

Lobato, L. V. C. (2016). Políticas sociais e modelos de bemestar social: Fragilidades do caso brasileiro. Saúde Debate, 40 (especial), p. 87-97.

Maciel, A., Jr. (2005). O problema da escolha e os impasses da clínica na era do biopoder. Em A. Maciel Jr., D. Kupermann, \& S. Tedesco (Orgs.). Polifonias: Clínica, política e criação. (Dissertação de Mestrado em Psicologia) - Universidade Federal Fluminense, Rio de Janeiro, RJ.

\footnotetext{
1 Com os mecanismos de segurança, vemos surgir um sistema fundamentalmente inverso do observado nas tecnologias disciplinares. Às técnicas disciplinares compete circunscrever um espaço no qual os mecanismos de poder funcionarão de forma centrípeta na medida em que isolam um espaço, intentando a tudo regulamentar, principalmente o detalhe - seu princípio é que até as coisas mais ínfimas não devem ser deixadas entregues a si mesmas. Racionalizado, o detalhe recebe um enfoque politizado, devendo as pequenas coisas serem organizadas para controle e utilização: o que é determinado é o que se deve fazer, por conseguinte todo o resto, sendo indeterminado, é proibido e deve ser corrigido com tanto maior cuidado quanto menor for sua infração. Com as disciplinas se parte de uma norma e é em relação ao adestramento efetuado pela mesma que é possível distinguir depois o normal do anormal. Já nos mecanismos de segurança, ao contrário, a operação de normalização vai consistir em fazer as diferentes curvas de normalidade já identificadas funcionarem umas em relação às outras e em fazer de sorte que as mais desfavoráveis sejam trazidas às que são mais favoráveis. Temos, portanto, aqui uma coisa que parte do normal e que se serve de certas distribuições consideradas mais favoráveis em todo caso que as outras e que irão servir de norma, ou seja, a norma encontrase em jogo no interior das normalidades diferenciais. O normal é que é primeiro, e é a partir do estudo dessas normalidades que a norma se fixa e desempenha seu papel operatório. (Foucault, 2008a).
} 


\section{H NTERAC̄öEM ET PSICOLOGIA}

Salgado, J. (2012). Corpo miserável, espírito empreendedor: Empreendedorismo, pobreza e desemprego no Brasil. Em Pauta. Revista da Faculdade de Serviço Social da Universidade do Estado do Rio de Janeiro, 10 (30), p. 129-147. https://doi.org/10.12957/rep.2012.5108

Santos, W. G. (1987). Cidadania e justiça: A política social na ordem brasileira. 2. ed. Rio de Janeiro: Campus.

Souza, C. R. A. (2012). Política pública de assistência social em análise: História, valores e práticas. (Dissertação de Mestrado). Universidade Federal de Sergipe, São Cristóvão, SE, Brasil.

Data de submissão: 04.11.2017

Data da primeira decisão editorial: 06.05.2018

Aprovado em: 10.06.2018

20 programa de transferência direta de renda, criado em 2004, tem como foco de atuação a população em situação de extrema pobreza e se baseia na garantia de renda, inclusão produtiva e no acesso aos serviços públicos. O Bolsa Família possui três eixos principais focados na transferência de renda, condicionalidades e ações e programas complementares visando promover o alívio imediato da pobreza. As condicionalidades reforçam o acesso a direitos sociais básicos nas áreas de educação, saúde e assistência social. Já as ações e programas complementares objetivam o desenvolvimento familiar, de modo que os beneficiários consigam superar a situação de vulnerabilidade. 